\title{
CLOCK expression identifies developing circadian oscillator neurons in the brains of Drosophila embryos Jerry H Houl ${ }^{\dagger 1,2}$, Fanny $\mathrm{Ng}^{\dagger 1,2,3}$, Pete Taylor ${ }^{1,2,4}$ and Paul E Hardin*1
}

\begin{abstract}
Address: ${ }^{1}$ Center for Research on Biological Clocks, Department of Biology, Texas A\&M University, 3258 TAMU, College Station, TX 77843, USA, ${ }^{2}$ Department of Biology and Biochemistry, University of Houston, 4800 Calhoun, Houston, TX 77204, USA, ${ }^{3}$ Department of Neuroscience, Tufts University School of Medicine, 136 Harrison Ave., Boston, MA 02111, USA and ${ }^{4}$ Department of Pediatrics, MD Anderson Cancer Center, 1515 Holcombe, Houston, TX 77030, USA
\end{abstract}

Email: Jerry H Houl - jhoul@mail.bio.tamu.edu; Fanny Ng - bio_sng@yahoo.com; Pete Taylor - taylor_pete@hotmail.com; Paul E Hardin* - phardin@mail.bio.tamu.edu

* Corresponding author †Equal contributors

Published: 18 December 2008

BMC Neuroscience 2008, 9:119 doi:10.1186/1471-2202-9-119
Received: 4 August 2008

Accepted: 18 December 2008

This article is available from: http://www.biomedcentral.com/I47I-2202/9/II9

(c) 2008 Houl et al; licensee BioMed Central Ltd.

This is an Open Access article distributed under the terms of the Creative Commons Attribution License (http://creativecommons.org/licenses/by/2.0), which permits unrestricted use, distribution, and reproduction in any medium, provided the original work is properly cited.

\begin{abstract}
Background: The Drosophila circadian oscillator is composed of transcriptional feedback loops in which CLOCK-CYCLE (CLK-CYC) heterodimers activate their feedback regulators period (per) and timeless (tim) via E-box mediated transcription. These feedback loop oscillators are present in distinct clusters of dorsal and lateral neurons in the adult brain, but how this pattern of expression is established during development is not known. Since CLK is required to initiate feedback loop function, defining the pattern of CLK expression in embryos and larvae will shed light on oscillator neuron development.
\end{abstract}

Results: A novel CLK antiserum is used to show that CLK expression in the larval CNS and adult brain is limited to circadian oscillator cells. CLK is initially expressed in presumptive small ventral lateral neurons $\left(\mathrm{s}-\mathrm{LN}_{\mathrm{v}} \mathrm{s}\right)$, dorsal neurons $2 \mathrm{~s}\left(\mathrm{DN}_{2} \mathrm{~s}\right)$, and dorsal neuron I $\mathrm{s}\left(\mathrm{DN}_{1} \mathrm{~s}\right)$ at embryonic stage (ES) 16, and this CLK expression pattern persists through larval development. PER then accumulates in all CLK-expressing cells except presumptive $\mathrm{DN}_{2}$ s during late $\mathrm{ES} 16$ and ES 17, consistent with the delayed accumulation of PER in adult oscillator neurons and antiphase cycling of PER in larval $\mathrm{DN}_{2}$ s. PER is also expressed in non-CLK-expressing cells in the embryonic CNS starting at ES 12. Although PER expression in CLK-negative cells continues in Clkjrk embryos, PER expression in cells that co-express PER and CLK is eliminated.

Conclusion: These data demonstrate that brain oscillator neurons begin development during embryogenesis, that PER expression in non-oscillator cells is CLK-independent, and that oscillator phase is an intrinsic characteristic of brain oscillator neurons. These results define the temporal and spatial coordinates of factors that initiate Clk expression, imply that circadian photoreceptors are not activated until the end of embryogenesis, and suggest that PER functions in a different capacity before oscillator cell development is initiated. 


\section{Background}

Most organisms exhibit daily rhythms in physiology, metabolism, and behavior that persist in the absence of environmental cues. In animals, these $\sim 24 \mathrm{hr}$ rhythms are controlled by circadian oscillators that reside in the central nervous system (CNS) and/or peripheral tissues. These oscillators are comprised of interlocked transcriptional feedback loops that regulate rhythmic gene expression within and downstream of the circadian timekeeping mechanism.

In Drosophila, the per/tim and Clk feedback loops control rhythmic transcription that peaks around dusk and dawn, respectively (reviewed in [1-3]). The per/tim feedback loop is initiated during mid-day, when CLK/CYC heterodimers bind E-box sequences to activate per and tim transcription $[4,5]$. Although per and tim mRNAs peak around dusk, phosphorylation of PER and TIM delays their peak accumulation to the late evening and promotes their nuclear localization [6-10]. After entering the nucleus, PER or PER-TIM heterodimers bind CLK to inhibit CLK-CYCdependent transcription [11-13]. In addition, clockwork orange (cwo) is also thought to inhibit per and tim transcription by competing for E-box binding with CLK-CYC [14-17]. PER and TIM are then degraded after dawn, thus relieving transcriptional inhibition. CLK-CYC initiates the Clk feedback loop by binding E-boxes to activate vri transcription [18]. VRI accumulates in parallel with vri mRNA during early evening and binds to V/P-boxes to repress $\mathrm{Clk}$ transcription $[19,20]$. Mutants that disrupt CLK-CYC transcriptional activity (e.g. $\mathrm{Clk}^{\mathrm{rk}}, c y \mathrm{C}^{01}$ ) exhibit constitutive high levels of Clk mRNA [21], indicating that Clk is activated independent of circadian oscillator function. Since CLK-CYC is required to initiate circadian feedback loop function, we hypothesize that the activation of $\mathrm{Clk}$ and $c y c$ during development determines oscillator cell identity.

Locomotor activity rhythms in adults can be synchronized by light-dark cycles in L1 larvae, but not in embryos, which indicates that the circadian oscillator is only functional after hatching [22]. Circadian oscillator cells are present in $\mathrm{LN}_{\mathrm{v}} \mathrm{s}, \mathrm{DN}_{1} \mathrm{~s}$ and $\mathrm{DN}_{2} \mathrm{~s}$ from $\mathrm{L} 1$ larval brains based on rhythmic expression of PER and TIM [23]. Since entrainment of oscillators to light is TIM dependent, and TIM accumulates in concert with PER about $6-8 \mathrm{~h}$ after their respective mRNAs (reviewed in [1-3]), per and tim transcription are expected to be initiated during embryogenesis. Indeed, per mRNA is detected in the central nervous system (CNS) of embryos [24,25], which implies that CLK and CYC accumulate in presumptive oscillator cells during embryonic development. To understand oscillator cell development in Drosophila, the spatial and temporal expression of CLK and PER was determined during embryogenesis.
In our previous studies, CLK GP47 antibody revealed CLK expression in circadian oscillator and non-oscillator cell nuclei from adult heads at all times of day [26]. Using a newly generated CLK antibody we show here that CLK is expressed exclusively in circadian oscillator cells, and that detection of CLK in non-oscillator cells in a previous study was due to cross-reactivity with DACHSHUND (DAC). During embryonic development PER is first expressed in the ventral nerve chord (VNC) at ES 12 and then the brain at ES 14, whereas CLK is not detected until ES 16 in brain cells that lack PER expression. These CLK-expressing brain cells correspond to $\mathrm{LN}_{\mathrm{v}} \mathrm{s}, \mathrm{DN}_{1} \mathrm{~s}$ and $\mathrm{DN}_{2} \mathrm{~s}$, and by the end of ES 16 or early ES 17 PER is detected in $\mathrm{LN}_{\mathrm{v}} \mathrm{s}$ and $\mathrm{DN}_{1} \mathrm{~s}$ but not $\mathrm{DN}_{2} \mathrm{~s}$. These results demonstrate that presumptive brain oscillator cells are present before functional oscillators are detected around the transition to larval life, suggest that the delayed appearance of PER accumulation in presumptive embryonic $\mathrm{DN}_{2} \mathrm{~S}$ gives rise to the antiphase cycling of PER in larval $\mathrm{DN}_{2} \mathrm{~s}$ compared to $\mathrm{LN}_{\mathrm{v}} \mathrm{s}$ and $\mathrm{DN}_{1} \mathrm{~s}$, and imply that PER has a clock-independent function in the VNC and brain in non-oscillator cells of embryos.

\section{Results \\ CLK expression is detected only in oscillator neurons}

We previously demonstrated CLK immunostaining in all circadian oscillator cells and some non-oscillator cells in adults [26]. One group of non-oscillator cells that showed CLK immunostaining was Kenyon Cells (KCs), which are involved in olfactory learning and memory [27]. To characterize CLK immunostaining during development, we co-stained L3 larval CNSs with CLK, oscillator cell marker PER, and the KC cell marker DAC [23,28-30]. As expected, we observed CLK staining in every PER-expressing cell, but also detected CLK in every DAC-expressing cell (Fig. 1). This surprising correspondence between CLK and DAC expression in non-oscillator cells suggests a relationship between $C l k$ and $d a c$ activation: $C l k$ and $d a c$ are activated by the same activator, Clk activates dac, or dac activates Clk. Alternately, CLK and DAC co-immunostaining could also result from cross-reactivity of CLK antiserum to DAC, though little, if any, sequence identity is evident between these two proteins (data not shown). Because CLK and DAC run at a similar apparent molecular weight of $\sim 130$ $\mathrm{kDa}$ on western blots $[13,31]$, we tested whether our CLK antiserum (GP47) cross-reacted with in vitro translated DAC. As expected, GP47 detected CLK on western blots, but this CLK antiserum also detected DAC (Fig. 2A). Competition with purified DAC protein blocked GP47 detection of DAC on western blots (Fig. 2B), confirming DAC cross-reactivity. Likewise, incubating L3 CNSs with purified DAC specifically blocks GP47 immunostaining in DAC expressing non-oscillator cells (Fig. 2C). GP47 antiserum detects more than the canonical 4 to $5 \mathrm{LN}_{\mathrm{v}} \mathrm{s}, 2$ $\mathrm{DN}_{2} \mathrm{~s}$, and $2 \mathrm{DN}_{1} \mathrm{~s}$ in L3 brains blocked with purified 

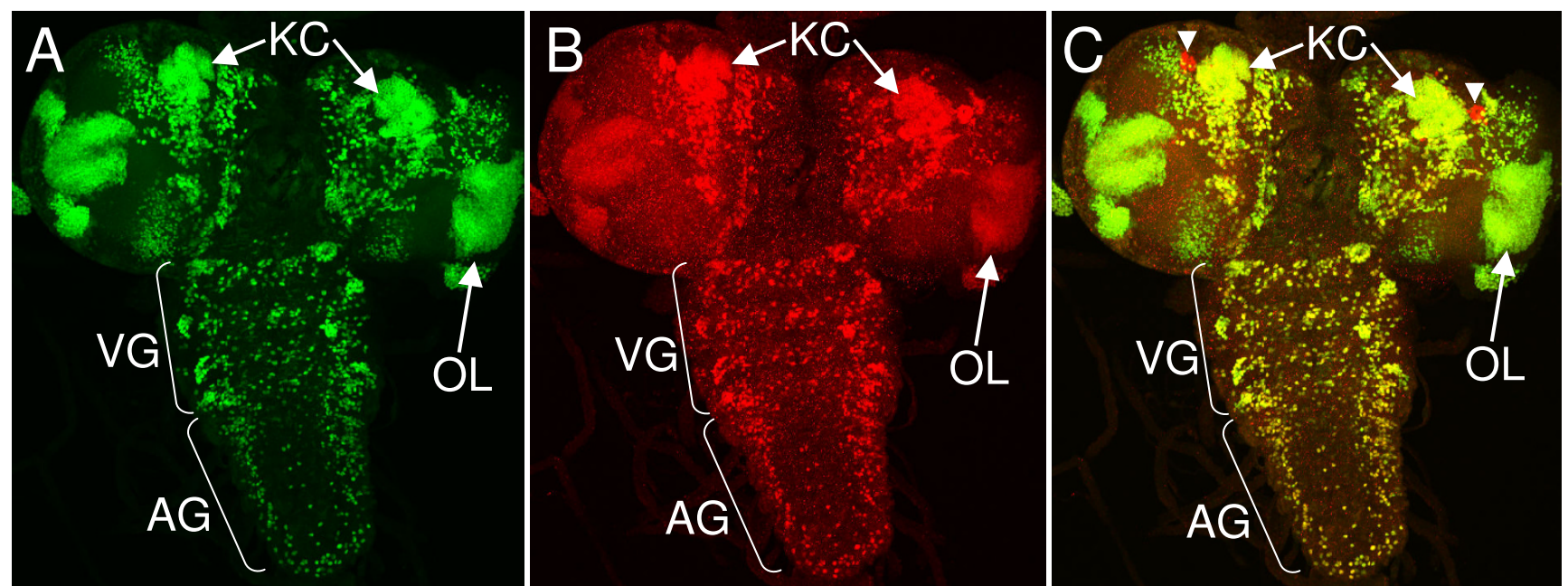

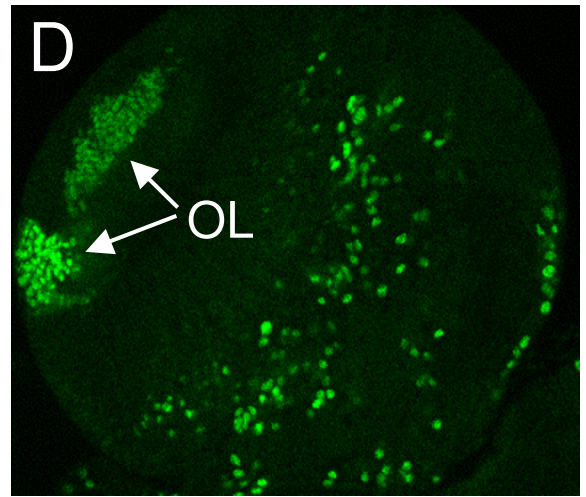

W.T. L3 DAC

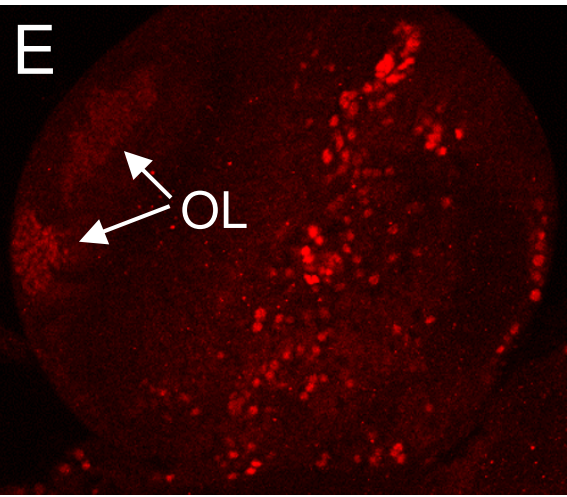

W.T. L3 CLK GP47

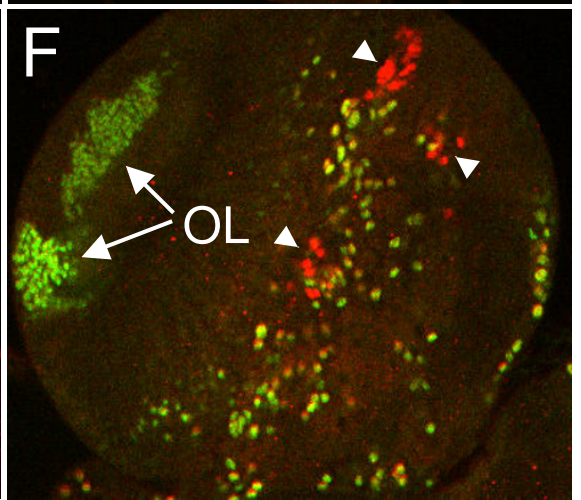

W.T. L3 DAC+CLK

\section{Figure I}

DAC is co-expressed with CLK in the CNS of L3 larvae. L3 larval brains were dissected and fixed at ZTI, immunostained with CLK and DAC antibodies, and imaged by confocal microscopy. (A-C) Projected Z-series images of the CNS, where dorsal is at the top. (A) DAC expression in the CNS. Arrows denote DAC immunoreactivity in Kenyon cells (KC) and the optic lobe (OL). (B) CLK expression in the same brain as panel A. Arrows denote CLK immunoreactivity in KCs and the OL. (C) Superimposed dual laser image of DAC and CLK immunostaining in the same larval CNS as panels A and B. Co-localization of DAC (green) and CLK (red) is seen as yellow. Arrowheads, CLK positive/DAC negative cells. (D-F) Magnified I $\mu \mathrm{m}$ optical section through the left hemisphere of an L3 larval brain. OL, optic lobe. (D) DAC immunostaining. (E) CLK immunostaining. (F) Superimposed dual laser image of DAC and CLK immunostaining. Arrowheads, CLK positive/DAC negative cells. Images are representative of three independent experiments. Six or more larval CNSs were examined in each experiment. Z-series images are projections over 32 optical sections at $2.5 \mu \mathrm{m}$ per optical section.

DAC. Although these additional cells could be due to incomplete blocking by DAC, they may also represent $\mathrm{DN}_{3} \mathrm{~s}, \mathrm{LN}_{\mathrm{d}} \mathrm{s}$, and/or l-LN $\mathrm{v}$, which have been detected previously in L3 brains [23,32]. CLK immunostaining in non-oscillator cells is also eliminated in the CNS of $\mathrm{dac}^{03}$ mutant larvae (Fig. 3), which lack DAC protein [33]. Taken together, these results demonstrate that CLK immunoreactivity (IR) in non-oscillator cells is due to crossreactivity with DAC, which implies that CLK expression is limited to oscillator cells.

Additional CLK antisera that we had generated were tested for cross-reactivity to DAC on western blots, and CLK antiserum GP50 showed no cross-reactivity to DAC (Fig. 4A). Based on the lack of CLK IR in non-oscillator cells from dac03 mutant larvae and L3 CNSs blocked with DAC antigen, we expected GP50 to detect CLK IR only in oscillator cells. Indeed, CLK and PER co-immunostained several clusters of cells including sLNvs, DN2s and DN1s in L3 larvae (Fig. 4B), but do not detect cells elsewhere in the CNS (compare CLK GP50 immunostaining with GP47 immunostaining in Fig. 1B, E), showing that CLK GP50 antiserum specifically detects oscillator cells in L3 brains. Four additional clusters of brain oscillator neurons are present in adult brains: LNds, l-LNvs, LPNs and DN3s $[34,35]$. Brains from adults collected at ZT23 were co- 

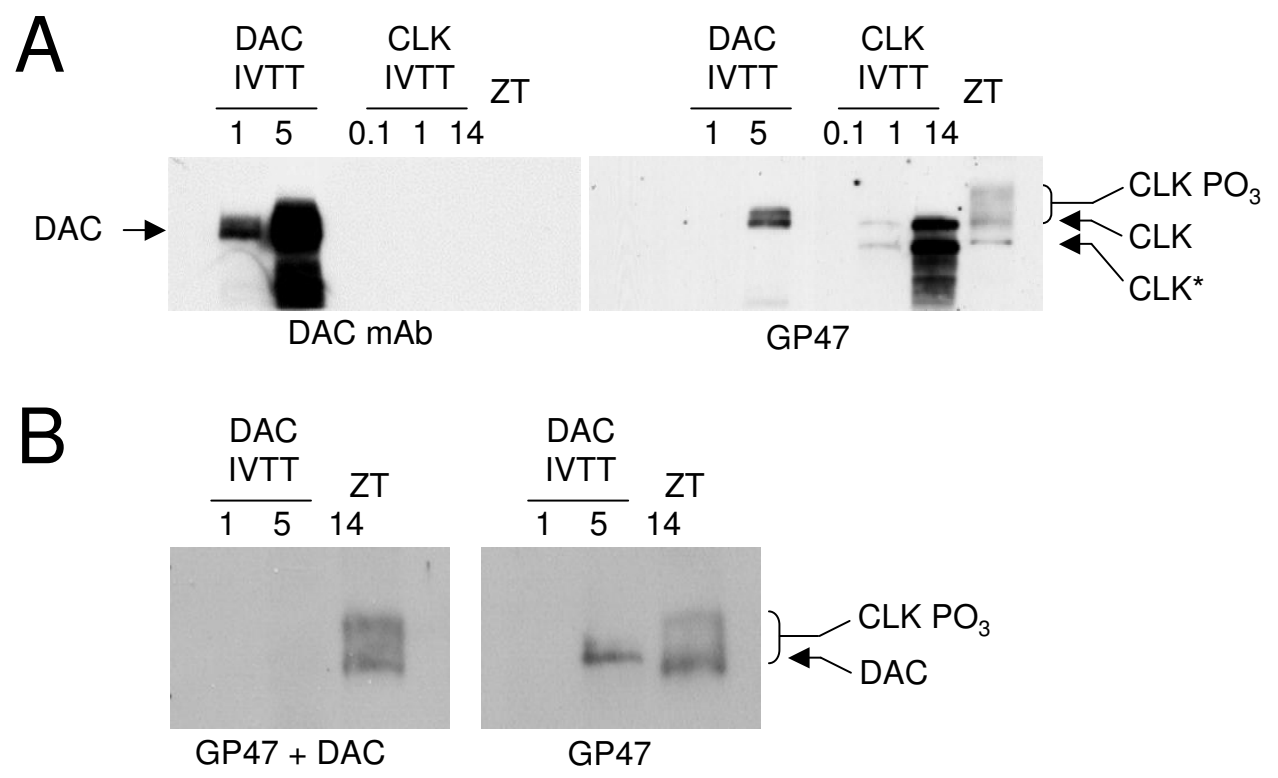

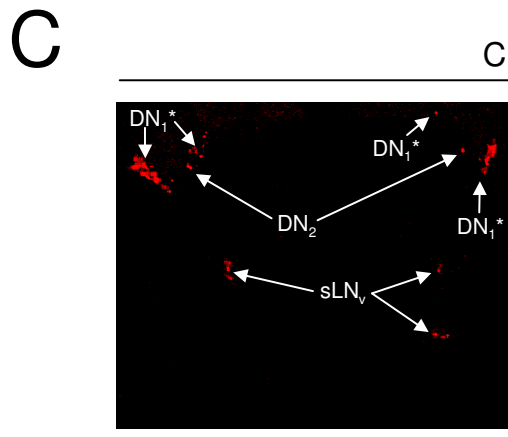

W.T. L3 CLK GP47

CLK GP47 + PER + DAC antibodies + DAC antigen

\section{Figure 2}

CLK GP47 antiserum cross-reacts with DAC. (A) Western blots containing I.0 $\mu \mathrm{l}$ and $5.0 \mu \mathrm{l}$ of in vitro transcribed and translated DAC (IVTT DAC), $0.1 \mu \mathrm{l}$ and I.0 u $\mu \mathrm{l}$ of in vitro transcribed and translated CLK (IVTT CLK), and I00 $\mu \mathrm{g}$ of head extract from flies collected at ZTI4 probed with either DAC monoclonal antibody (DAC mAb) (left) or CLK GP47 antiserum (GP47) (right). (B) Western blots of samples as denoted in panel A probed with CLK GP47 and $10 \mu \mathrm{g}$ of purified DAC (GP47 + DAC) (left) or CLK GP47 alone (GP47) (right). (C) Dissected CNSs from wild-type L3 larvae collected at ZT2I were incubated with CLK GP47 antiserum, PER antiserum, DAC monoclonal antibody and $10 \mu \mathrm{g}$ of purified DAC antigen. A $32 \mu \mathrm{m}$ projected Z-series image of CLK GP47 IR alone (W.T. CLK), PER IR alone (W.T. PER), DAC IR alone (W.T. DAC), and merged CLK GP47, PER and DAC IR (W.T. merged). Arrows denote brain oscillator cells. s-LN $\mathrm{v}_{v}$, small ventral lateral neurons; $\mathrm{DN}_{2}$, dorsal neuron $2 \mathrm{~s} ; \mathrm{DN}_{1}{ }^{*}$, dorsal neuron I s plus additional brain oscillator neurons that may include $\mathrm{DN}_{3} \mathrm{~s}$, I-LN $\mathrm{LN}_{\mathrm{v}} \mathrm{s}$ and $\mathrm{LN}_{\mathrm{d}} \mathrm{s}$.

immunostained with GP50 and PER to determine if CLK expression is limited to oscillator neurons. CLK IR is also detected exclusively in oscillator cells from adult brains and is reduced or eliminated in brains from ClkJrk adults (Fig. 5), which express very low levels of truncated CLK protein (Fig. 6). These results demonstrate that GP50 specifically detects CLK, and that CLK is expressed exclusively in circadian oscillator cells in wild-type adult brains. Given that CLK is detected specifically in brain oscillator neurons in adults and L3 larvae, we used CLK GP50 antiserum to determine when brain oscillator neurons first appear during development.

\section{PER is expressed before CLK during embryogenesis}

To determine whether CLK is expressed in presumptive brain oscillator cells, embryos between $0 \mathrm{~h}$ and $24 \mathrm{~h}$ old were collected at CT33 and co-immunostained with PER and CLK. PER IR is detected in a segmented pattern along VNC as early as ES 12 (Fig. 7A, B), consistent with previous in situ hybridization results in embryos $[24,25]$. PER in the $\mathrm{VNC}$ encompasses more cells, increases in intensity, and expands into the brain by ES 15 (Fig. 7C-H). Loss of PER IR in $p e r^{01}$ mutant confirms that this IR represents true PER expression (Fig. 7I). Surprisingly, no CLK IR is detected in PER-expressing cells, indicating that per is not 


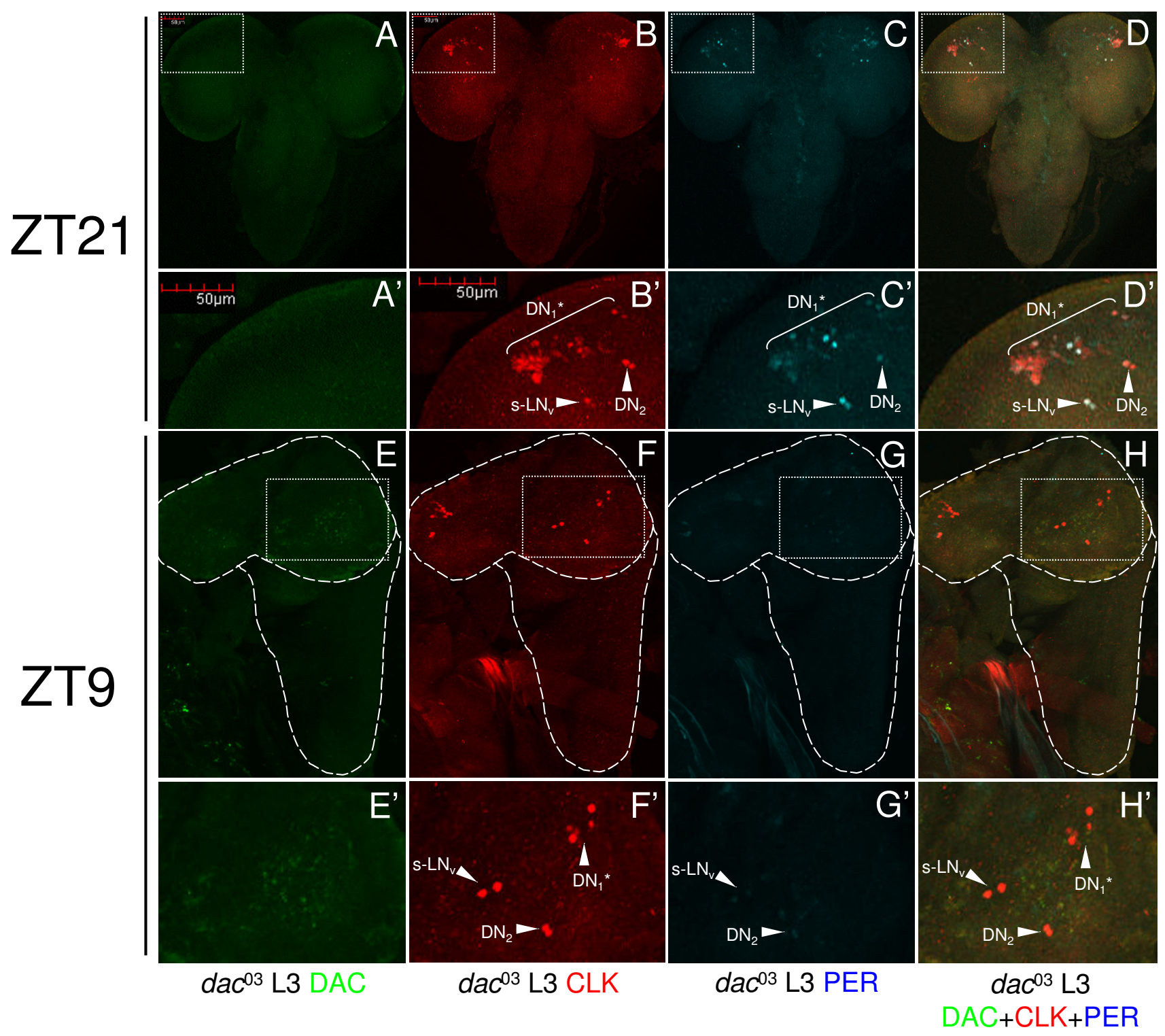

Figure 3

DAC is required for CLK cross-reactivity in non-oscillator cells. CNSs were dissected from dac ${ }^{03}$ mutant $L 3$ larvae collected at ZT2I and ZT9, immunostained with DAC, CLK GP47, and PER antibodies, and imaged by confocal microscopy. (A-D, E-H) Projected Z-series images of the CNS from L3 larvae are shown, where dorsal is at the top. (A-D') CNS from an L3 larva collected at ZT2I was imaged for DAC (A), CLK (B), PER (C) or DAC, CLK and PER (D) immunostaining. Boxed region in panels $A-D$ is magnified in panels $A^{\prime}-D^{\prime}$, respectively. ( $\left.B^{\prime}-C^{\prime}\right)$ Brackets denote CLK and/or PER IR in DN ${ }^{*}$ neurons, and arrowheads denote CLK and/or PER IR in s-LN $\mathrm{V}_{v}$ and $\mathrm{DN}_{2}$ neurons. $D N_{1} *, s-\mathrm{LN}_{\mathrm{v}}$, and $\mathrm{DN}_{2}$ neurons are as defined in the legend for Fig. 2. Co-localization of CLK (red) and PER (blue) appears as white. (E-H') CNS from an L3 larva collected at ZT9 was imaged for DAC (E), CLK (F), PER (G) or DAC, CLK, and PER $(H)$ immunostaining. Boxed region in panels E-H is magnified in panels $E^{\prime}-H^{\prime}$, respectively. (F'-H') Arrowheads denote CLK and/or PER IR in $D_{N}{ }^{*}, s-L N_{v}$, and $D_{2} N_{2}$ neurons. Images are representative of three independent experiments at each time point. At least three larval CNSs were examined for each experiment. Z-series images are projections over 33 optical sections at $2.5 \mu \mathrm{m}$ per optical section.

activated by CLK-CYC during these early developmental stages. The CLK-CYC independent activation of per is similar to the situation in ovaries, where PER expression is not associated with circadian oscillator function [36]. To ensure that CLK expression below detectable levels does not activate PER at ES 12-15, Clk ${ }^{\text {jrk }}$ embryos were immunostained for PER. These Clk ${ }^{\text {rk }}$ embryos show PER staining in the brain and VNC identical to that in wild-type embryos at ES 15 (Fig. 7J). 


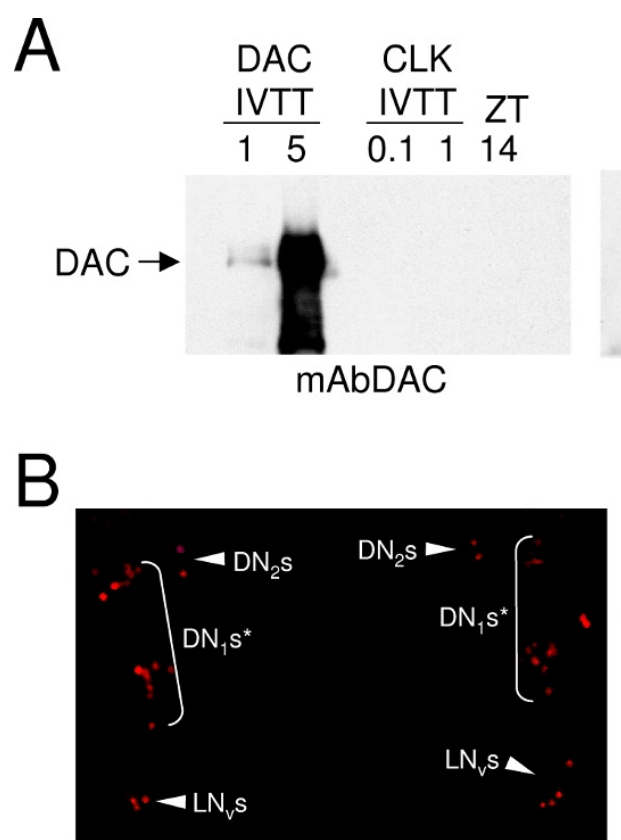

W.T. L3 ZT23 CLK GP50

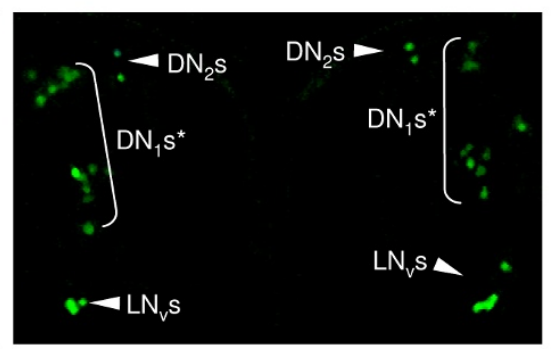

W.T. L3 ZT23 PER

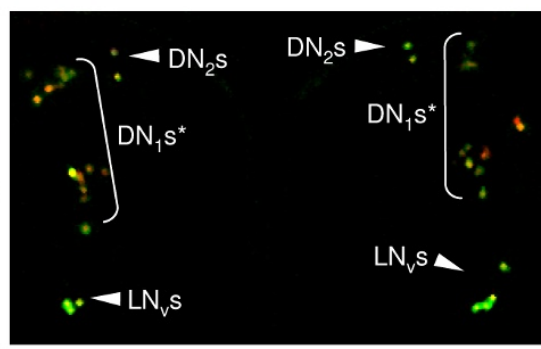

W.T. L3 ZT23 CLK + PER

\section{Figure 4}

CLK GP50 antibody does not cross-react with DAC and detects CLK IR only in oscillator cells. (A) Western blots containing I. $0 \mu \mathrm{l}$ and $5.0 \mu \mathrm{l}$ of in vitro transcribed and translated DAC (IVTT DAC), $0.1 \mu \mathrm{l}$ and I.0 $\mu \mathrm{l}$ of in vitro transcribed and translated CLK (IVTT CLK), and $100 \mu \mathrm{g}$ of head extract from flies collected at ZTI4 probed with either DAC monoclonal antibody (mAbDAC) (left) or CLK GP50 antiserum (GP50) (right). (B) Wild-type L3 larval brains were dissected and fixed at ZT23, immunostained with CLK and PER antibodies, and imaged by confocal microscopy. Images show an $18 \mu \mathrm{m}$ Z-series projection of the CNS, where dorsal is at the top. CLK GP50 (left panel), PER (Middle panel) or merged CLK GP50 + PER (right panel) immunostaining in $\mathrm{DN}_{1} *$ neurons (brackets) and $\mathrm{DN}_{2}$ or $\mathrm{s}-\mathrm{LN}_{\mathrm{v}}$ neurons (arrowheads) in both brain hemispheres. $\mathrm{DN} \mathrm{N}_{1}$, $s-L_{v}$, and $\mathrm{DN}_{2}$ neurons are as defined in the legend for Fig. 2. Co-localization of CLK (red) and PER (green) is shown as yellow. All images are representative of three or more independent experiments.

\section{CLK expression preceeds PER expression in presumptive brain oscillator cells during embryogenesis}

Early in ES 16, weak CLK immunoreactivity is first detected in brain cells that do not express PER (Fig. 8AC). During mid to late ES 16, CLK expression becomes stronger and expands to additional cells in the dorsal brain (Fig. 8D-F). In addition, PER starts to be detected in CLK positive cells in the ventral portion of the brain (Fig. 8F). By ES 17, CLK positive cells form three distinct clusters in each brain hemisphere, with two dorsal cells, four ventral cells, and two cells between and slightly posterior to these dorsal and ventral clusters (Fig. 8G-I). The positions of these CLK positive cells are reminiscent of oscillator cells in larvae; a dorsal cluster of $\mathrm{DN}_{1} \mathrm{~s}$, a ventral cluster of s- $\mathrm{LN}_{\mathrm{v}} \mathrm{s}$, and a medial cluster of $\mathrm{DN}_{2} \mathrm{~s}[23,37]$.

Although PER is expressed in some CLK-positive dorsal brain neurons, two cells situated between the most dorsal and ventral CLK-expressing brain cells show little or no PER expression (Fig. 8I). Based on their location, these
CLK positive/PER negative cells likely correspond to $\mathrm{DN}_{2} \mathrm{~s}$. In larvae, PER cycling in $\mathrm{DN}_{2} \mathrm{~s}$ is antiphase compared to LNs and $\mathrm{DN}_{1} \mathrm{~s}$ [23], which is consistent with the absence of PER expression in the presumptive $\mathrm{DN}_{2} \mathrm{~s}$ of embryos during the late night and early morning. These results suggest that CLK is expressed in $\mathrm{LN}_{\mathrm{v}} \mathrm{s}, \mathrm{DN}_{1} \mathrm{~s}$, and $\mathrm{DN}_{2} \mathrm{~s}$ starting at ES 16, followed by PER expression in $\mathrm{DN}_{1} \mathrm{~s}$ and $\mathrm{LN}_{\mathrm{v}} \mathrm{s}$ during late ES 16 and ES 17. The timeline for CLK and PER expression in embryos is the same whether they are collected at CT49 (1 hour after subjective dawn) or CT37 (1 hour after subjective dusk) (data not shown), indicating that CLK and PER expression are controlled developmentally and are not influenced by the time at which embryos were laid during the circadian cycle.

To confirm that CLK is expressed in larval $\mathrm{LN}_{\mathrm{v}} \mathrm{s}, \mathrm{DN}_{1} \mathrm{~s}$, and $\mathrm{DN}_{2} \mathrm{~s}$, L1 larvae collected at ZT13 and ZT1 were immunostained with CLK GP50 and PER antisera. As expected, CLK is expressed in all PER-expressing cells at ZT21, which 


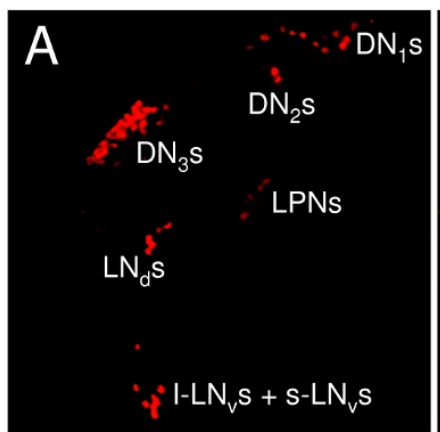

W.T. CLK

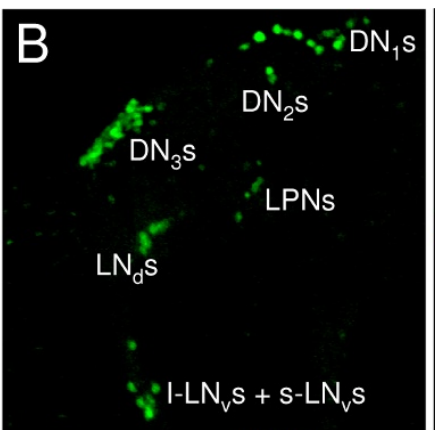

W.T. PER

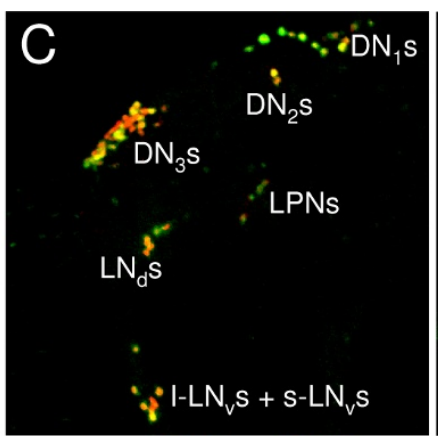

W.T. CLK + PER

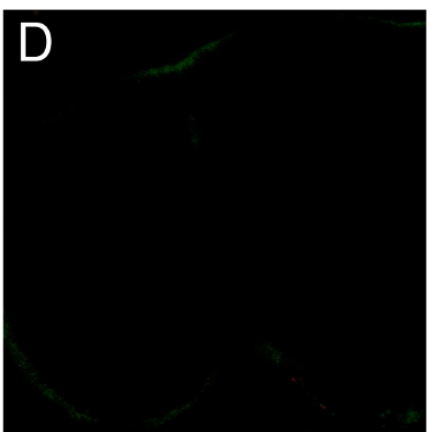

Clksk CLK + PER

\section{Figure 5}

CLK GP50 antibody only detects oscillator cells in adult brains. Brains were dissected from adults collected at ZT2I, immunostained with CLK GP50 and PER antisera, and imaged by confocal microscopy. (A-C) A $66 \mu \mathrm{m}$ projected Z-series image of a wild-type adult fly brain, where lateral is left and dorsal is top. CLK (A), PER (B) and CLK + PER (C) IR is detected in dorsal neurons ( $D N_{1} s, D N_{2} s, D N_{3} s$ ), lateral posterior neurons (LPNs), and lateral neurons $\left(s-L_{v} s+1-L N_{v} s\right)$. Co-localization of CLK (red) and PER (green) is shown as yellow. (D) A $64 \mu \mathrm{m}$ projected Z-series image of a ClkJrk adult fly brain, where lateral is left and dorsal is top. No CLK or PER staining is detected. All images are representative of three or more independent experiments.

includes $\mathrm{LN}_{\mathrm{v}} \mathrm{s}$ and $\mathrm{DN}_{1} \mathrm{~s}$ (Fig. 9A-C). CLK is also expressed in the presumed $\mathrm{DN}_{2} \mathrm{~s}$, which lack PER expression at this time. In contrast, PER is co-expressed with CLK in $\mathrm{DN}_{2} \mathrm{~s}$ at ZT9, but is absent in $\mathrm{LN}_{\mathrm{v}} \mathrm{s}$ and $\mathrm{DN}_{1} \mathrm{~s}$ (Fig. 9D-
F). In addition, little or no PER IR is detected at either time point in the VNC. From these experiments, we conclude that CLK is constantly expressed only in brain oscillator cells from L1 larvae; whereas PER is rhythmically

\section{A}

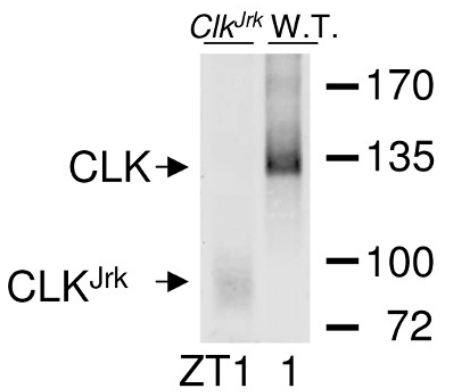

Short exposure

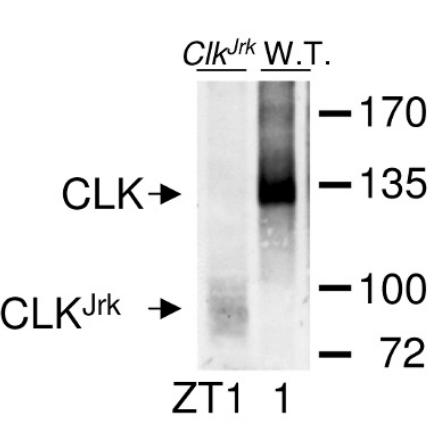

Long exposure
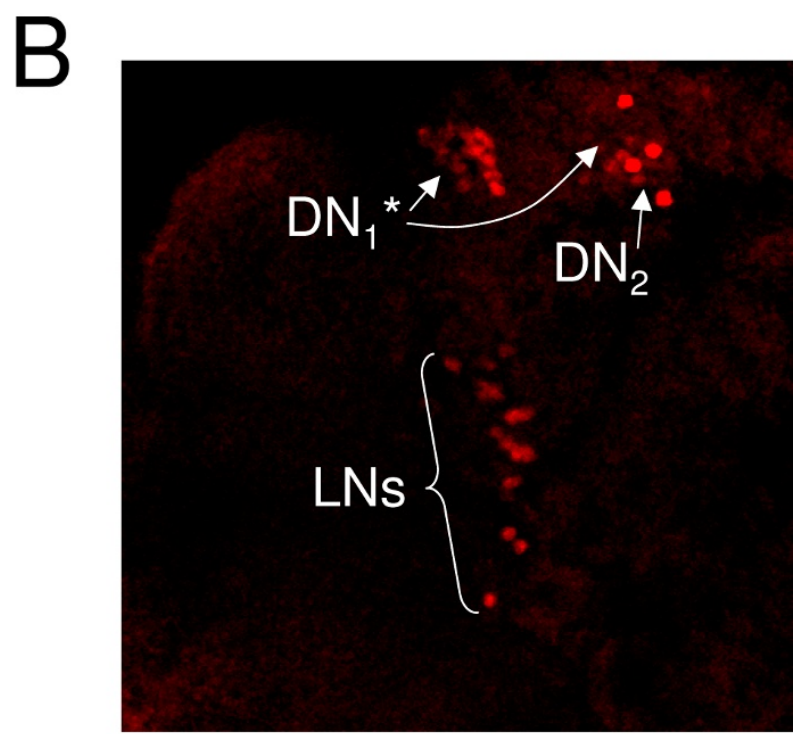

Clk ${ }^{\text {rk }}$ L3 CLK

\section{Figure 6}

Truncated CLKJrk protein accumulates to low levels. (A) Western blot containing $100 \mu \mathrm{g}$ of head extract from ClkJrk or wild-type flies collected at ZTI and probed with CLK GP50 antiserum. Full length CLK and truncated CLKJrk proteins are denoted in short (left) or long (right) exposures of the blot. (B) Brains from ClkJrk L3 larvae were dissected and fixed at ZTI, immunostained with a lower dilution of CLK GP50 antibody (diluted I:I000 instead of I:3000), and imaged by confocal microscopy. Images show a $28 \mu \mathrm{m}$ Z-series projection of a right brain hemisphere, where dorsal is at the top. CLK GP50 immunostaining is detected in $\mathrm{DN}_{1}{ }^{*}, \mathrm{DN}_{2}$ and $\mathrm{LN}$ cells. $\mathrm{DN}{ }_{1}^{*}$ and $\mathrm{DN}_{2}$ cells are as defined in the legend for Fig. 2, and $\mathrm{LN}$ cells include $s-L N_{v} s, I-L N_{v} s$ and $L N_{d} s$. All images are representative of three or more independent experiments. 


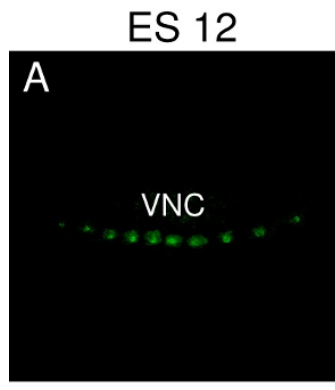

W.T. PER

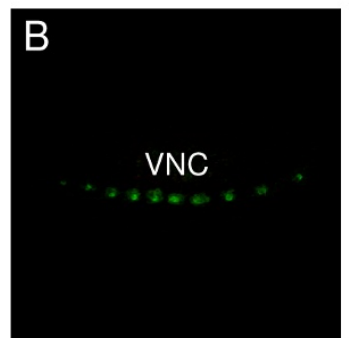

W.T. CLK+PER

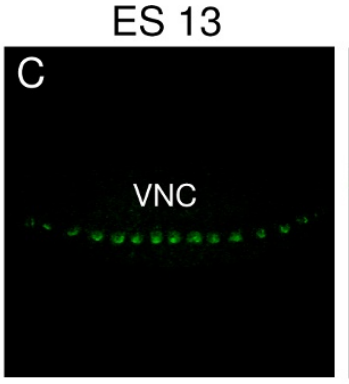

W.T. PER

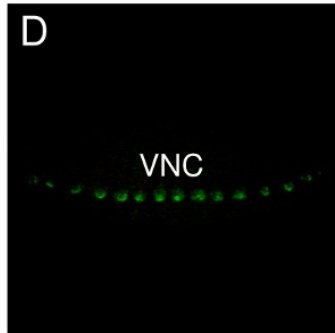

W.T. CLK+PER

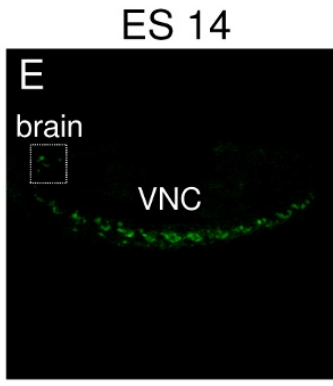

W.T. PER

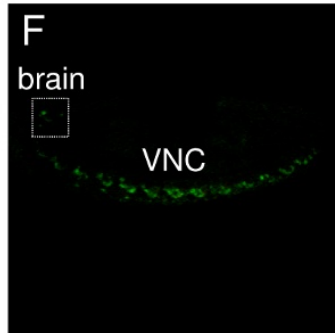

W.T. CLK+PER

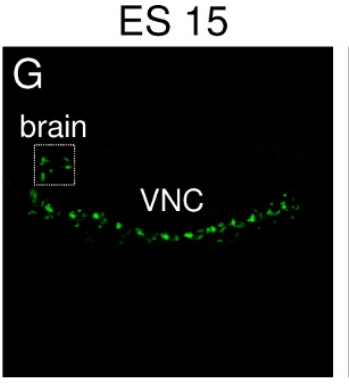

W.T. PER

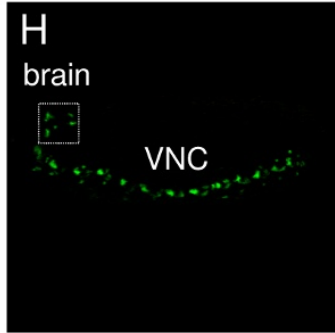

W.T. CLK+PER
ES 15

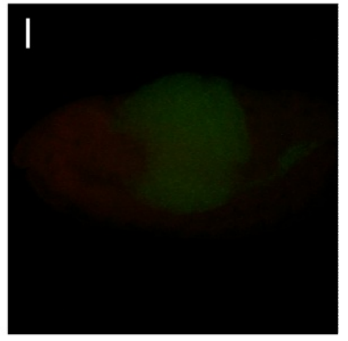

per ${ }^{01}$ CLK+PER

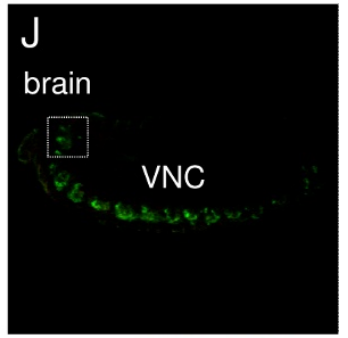

Clk ${ }^{\mathrm{rk}} \mathrm{CLK}+\mathrm{PER}$

\section{Figure 7}

PER and CLK expression in ES I 2 - ES 15 embryos. $0 \mathrm{~h}-24 \mathrm{~h}$ wild-type (W.T.), per ${ }^{0 \mathrm{l}}$, or Clk ${ }^{\mathrm{jrk}}$ embryos were collected at CT33, immunostained with CLK and PER antisera, and imaged by confocal microscopy. (A, B) $12 \mu \mathrm{m}$ Z-series projection of PER (A) or CLK + PER (B) IR in the VNC of a W.T. embryo during ES I2. (C, D) $20 \mu \mathrm{m}$ Z-series projection of PER (C) or CLK + PER (D) IR in the VNC of a W.T. embryo during ES I3. (E, F) I8 $\mu \mathrm{m}$ Z-series projection of PER (E) or CLK + PER (F) IR in the brain (box) and VNC of a W.T. embryo during ES I4. (G, H) $30 \mu \mathrm{m}$ Z-series projection of PER (G) or CLK + PER (H) IR in the brain (box) and VNC of a W.T. embryo during ES I5. (I) $42 \mu \mathrm{m}$ Z-series projection of PER (E) or CLK + PER (F) IR of a perlㅣ embryo during ES I5. (J) $22 \mu \mathrm{m}$ Z-series projection of PER (E) or CLK + PER (F) IR in the brain (box) and VNC of a ClkJrk embryo during ES I5. Co-localization of CLK (red) and PER (green) is shown as yellow. All images are representative of three or more independent experiments.

expressed only in oscillator cells from L1 larval brains with high levels at ZT2 1 in $\mathrm{LN}_{\mathrm{v}} \mathrm{s}$ and $\mathrm{DN}_{1} \mathrm{~s}$ and at ZT9 in $\mathrm{DN}_{2} \mathrm{~s}$.

\section{Discussion and conclusion \\ CLK is expressed exclusively in oscillator cells}

CLK immunostaining was previously detected in all oscillator cells and many non-oscillator cells from adult brains [26]. CLK expression in non-oscillator cells was coincident with that of DAC, which is structurally related to the winged helix/forked-head subfamily of helix-turn-helix DNA binding proteins [38]. Here, we find that CLK IR in non-oscillator cells is due to cross-reactivity between CLK GP47 antiserum and DAC (Fig. 1A-F). We also characterized another CLK antiserum, GP50, and demonstrated that it does not cross-react with DAC on westerns (Fig. 4A). Immunostaining of adult brains with GP50 confirms that CLK is expressed only in oscillator neurons (Fig. 4B). The oscillator cell-specific expression of Clk implies that CLK is required for the development and/or function of these cells.
This cell type specificity is consistent with the induction of oscillator cell function, when Clk is expressed in ectopic locations [39]. However, CLK expression cannot induce ectopic oscillators in any cell type, suggesting that other factors critical for oscillator function are not activated by CLK or the CLK-dependent developmental programs are incompatible with the development of many cell types. In the loss-of-function Clk ${ }^{\text {rk }}$ mutant, expression of direct CLK-CYC target genes, per, tim, vri, and $P d p 1 \varepsilon$ is abolished $[4,18,19]$, making it difficult to positively identify oscillator cells. Though peripheral oscillator tissues (e.g. eye, Malpighian tubule, gut, antenna) apparently develop normally in Clk ${ }^{\mathrm{Jrk}}$ flies, the loss of oscillator neuron markers in $C k^{\text {srk }}$ flies makes it difficult to determine whether these neurons are present. One exception to this is $1-\mathrm{LN}_{\mathrm{v}} \mathrm{s}$, which continue to express PDF in Clk $k^{\text {rk }}$ flies [40]. Determining whether CLK contributes to oscillator cell development depends on the availability of oscillator cell markers that are expressed independent of CLK-CYC or rescue of a lossof-function Clk mutant, upon CLK induction in adults. 


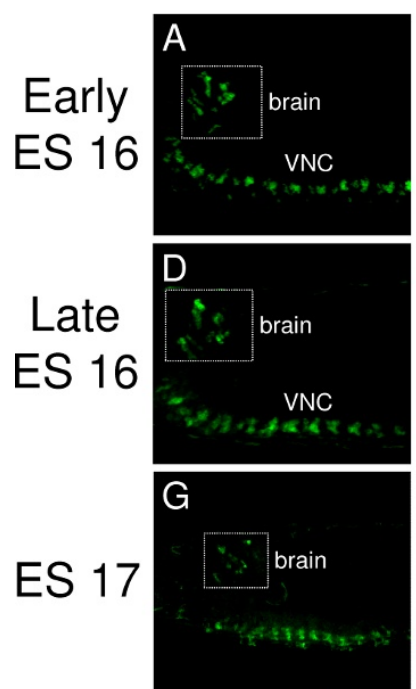

W.T. PER
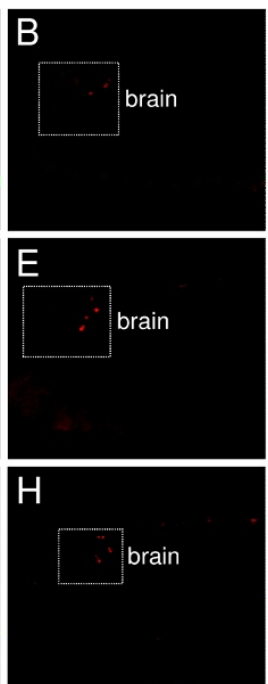

W.T. CLK
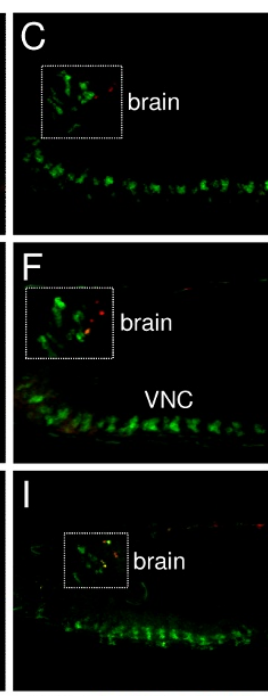

W.T.PER+CLK
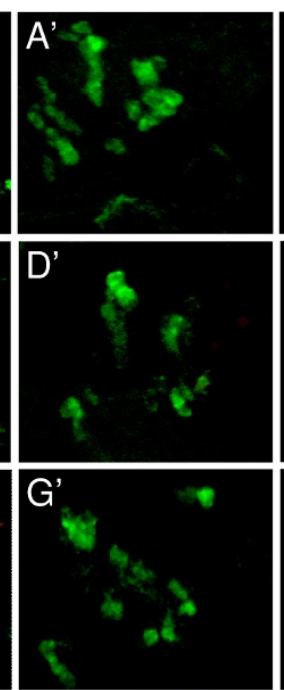

W.T. PER

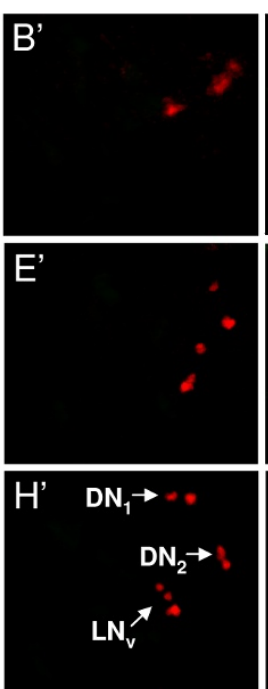

W.T. CLK

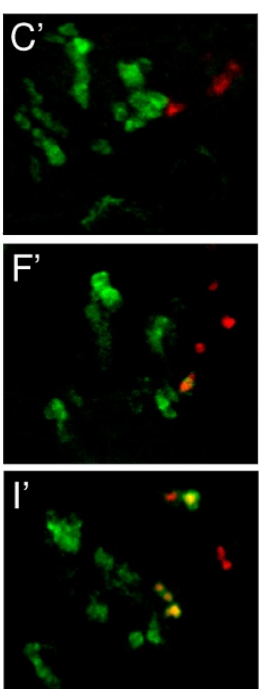

W.T. PER+CLK

\section{Figure 8}

CLK and PER expression in embryos during ES I6 and ES I7. $0 \mathrm{~h}-24 \mathrm{~h}$ wild-type (W.T.) embryos were collected at CT33, immunostained with CLK and PER antisera, and imaged by confocal microscopy. Anterior is to the left and dorsal is on the top. (A-C) $58 \mu \mathrm{m}$ Z-series projection of PER (A), CLK (B) or CLK + PER (C) IR in the brain (box) and VNC during early ES 16. ( $\left.A^{\prime}-C^{\prime}\right)$ Magnified view of the boxed brain regions in panels A-C, respectively. (D-F) I8 $\mu \mathrm{m}$ Z-series projection of PER (D), CLK (E) or CLK + PER (F) IR in the brain (box) and VNC during late ES I6. (D'-F') Magnified view of the boxed brain regions in panels D-F, respectively. (G-I) $20 \mu \mathrm{m}$ Z-series projection of PER (G), CLK (H) or CLK + PER (I) IR in the brain (box) and VNC during ES I7. (G'-I') Magnified view of the boxed brain regions in panels G-I, respectively. Co-localization of CLK (red) and PER (green) is shown as yellow. All images are representative of three or more independent experiments.

\section{Oscillator cell development}

In adults, CLK-dependent activation of the feedback regulator per is required for oscillator function [4,5], thus we expect that Clk would be expressed before per during development. However, per mRNA and protein are expressed in the VNC starting at ES 12 and in the brain at ES 14 (Fig. 7A-F), well before CLK is detected in the brain at ES 16. This early PER expression in the VNC and brain is independent of Clk because it persists in the Clk ${ }^{\mathrm{Jrk}}$ mutant and does not overlap with CLK later in development. The role of PER in CLK negative cells during embryogenesis is unknown, but it is possible that PER modulates transcription by targeting other bHLH-PAS transcription factors (e.g. SINGLE-MINDED) expressed in these cells [41]. Regardless of the role PER plays, the lack of obvious developmental defects in per ${ }^{01}$ flies suggests that per is not critical for embryonic development. In larvae, the intensity of PER IR in CLK-negative brain cells and the VNC decreases drastically (Figs. 3, 4, 9), consistent with previous results [19].

CLK can be detected in 2-4 cells in each brain hemisphere starting at early to mid ES 16, and expands during ES 17 to approximately eight CLK-positive cells in each brain hemisphere (Fig. 8). These cells are spatially segregated into three groups that correspond to larval $\mathrm{LN}_{\mathrm{v}} \mathrm{s}, \mathrm{DN}_{2} \mathrm{~s}$, and $\mathrm{DN}_{1} \mathrm{~s}$ (Fig. 8D-I). PER can be detected in some CLKpositive brain cells starting as early as the end of ES 16 (Fig. 8D), or about 16 h post-fertilization. During ES 17, PER IR increases in intensity and encompasses all four $\mathrm{LN}_{\mathrm{v}} \mathrm{s}$ and both $\mathrm{DN}_{1} \mathrm{~s}$ (Fig. 8G-I). The 3-6 h delay between CLK detection and PER detection in embryonic brain cells is similar to the delay between the accumulation of per mRNA and protein in adults $[42,43]$, and suggests that once CLK-CYC initiates per transcription in embryos, PER accumulation is delayed by the same DBT-dependent PER degradation mechanism described in adults. The initiation of molecular oscillator function at ES 17 coincides with the existence of light-entrainable oscillators that mediate behavioral rhythms in adults; a $12 \mathrm{~h}$ light pulse ending $6 \mathrm{~h}$ before larval hatching didn't synchronize behavioral rhythms of adults, but a $12 \mathrm{~h}$ light pulse ending at the time of larval hatching did synchronize behavioral rhythms in adults [22]. The initiation of oscillator function by CLK in embryos is also consistent with Clk's unique ability to initiate oscillator function when expressed in certain ectopic cells [39]. When combined with these previous studies, our results support a model whereby CLK expression initiates circadian oscillator function in brain neurons at ES 16, and these brain neurons go on to control rhythms in locomotor activity in adults. 


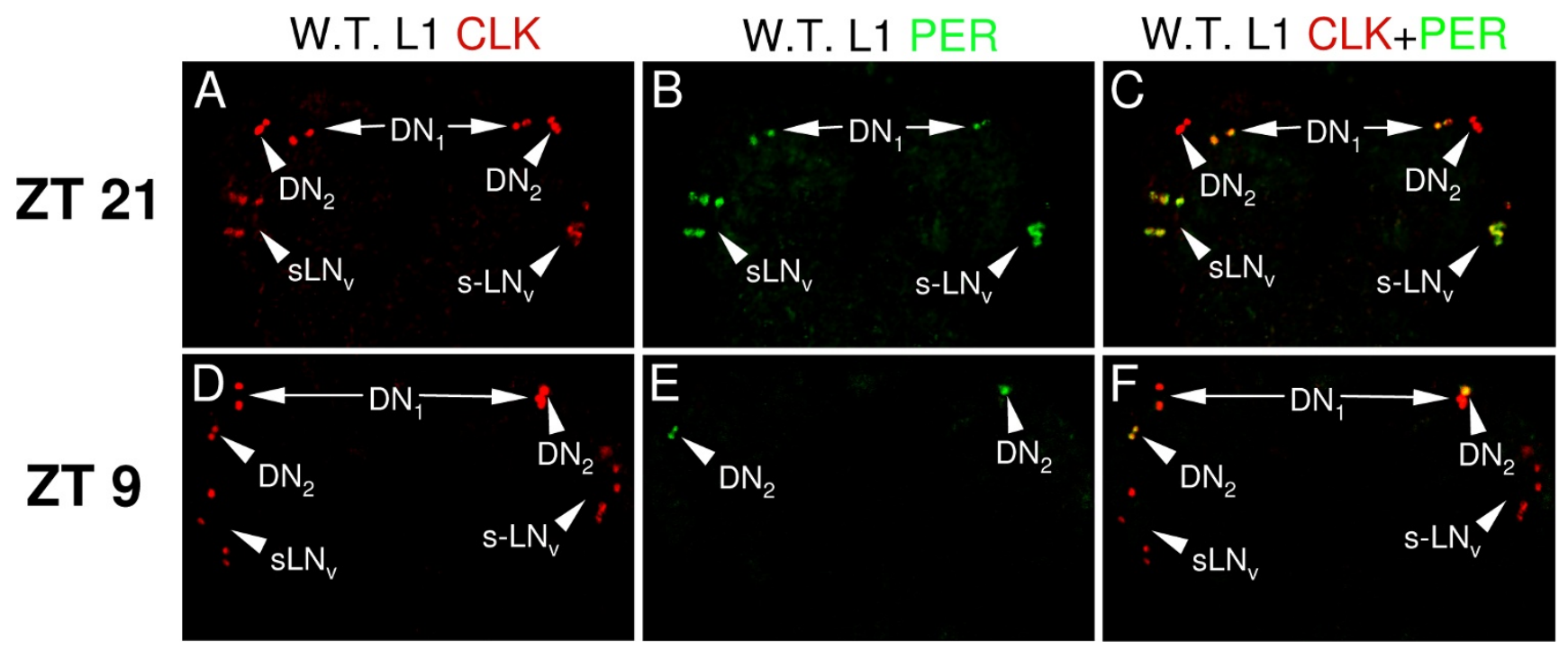

\section{Figure 9}

Antiphase cycling of PER expression in $\mathbf{D N}_{\mathbf{2}} \mathbf{s}$ from LI larvae. CNSs were dissected from wild-type (W.T.) LI larvae collected at ZT2I and ZT9, immunostained with CLK and PER antibodies, and imaged by confocal microscopy. Dorsal is at the top. (A-C) A $21 \mu \mathrm{m}$ projected Z-series image of CLK (A), PER (B), and merged CLK + PER (C) IR in W.T. LI larvae collected at ZT2I. CLK IR is present in $D_{1}, D N_{2}$ and s-LN $N_{y}$ cells $(A, C)$ and PER IR is detected in DNI and s-LNv cells (B, C). (D-F) A $22 \mu \mathrm{m}$ projected Z-series image of CLK (D), PER (E), and merged CLK + PER (F) IR in W.T. LI larvae collected at ZT9. CLK is present in $\mathrm{DN}_{1}, \mathrm{DN}_{2}$ and $s-\mathrm{LN}_{v}$ cells $(\mathrm{D}, \mathrm{F})$ and PER IR is detected in $\mathrm{DN}_{2}$ cells $(\mathrm{E}, \mathrm{F})$. Co-localization of CLK (red) and PER (green) is shown in yellow. All images are representative of three or more independent experiments.

CLK is expressed in all three groups of oscillator neurons during ES 16 and ES 17, but PER is only detected in $\mathrm{LN}_{\mathrm{v}} \mathrm{s}$ and $\mathrm{DN}_{1}$ s during this time. The delayed onset of PER accumulation in $\mathrm{DN}_{2} \mathrm{~S}$ is intriguing, considering that the $\mathrm{DN}_{2} \mathrm{~S}$ oscillator is antiphase compared to those in larval $\mathrm{LN}_{\mathrm{v}} \mathrm{s}$ and $\mathrm{DN}_{1} \mathrm{~s}$ [23]. The antiphase cycling of oscillator in $\mathrm{DN}_{2} \mathrm{~s}$ can be brought into phase with oscillators in $\mathrm{LN}_{\mathrm{v}} \mathrm{s}$ and $\mathrm{DN}_{1}$ s by expressing CRY in $\mathrm{DN}_{2} \mathrm{~s}$ [44], demonstrating that this antiphase cycling is CRY-dependent. Whether CRY also acts to control antiphase cycling in embryonic $\mathrm{DN}_{2} \mathrm{~S}$ will be investigated. In any case, our results demonstrate that antiphase cycling of oscillators in $\mathrm{DN}_{2} \mathrm{~s}$ is developmentally regulated and light independent.

The activation and maintenance of Clk transcription in developing and adult Drosophila is not well understood. The basic zipper protein PDP1ع is involved in maintaining Clk activation in adults [19], but does not appear to be the primary $\mathrm{Clk}$ activator [45]. One approach to defining Clk activators in embryos is to first determine which cells within the Drosophila embryonic brain express CLK base on co-expression of marker genes $[46,47]$. Once CLKexpressing cells have been identified, transcriptional activators expressed in these cells can be tested singly or in combination for their ability to activate Clk. Identifying factors that activate $C l k$ in a cell-specific manner will ultimately reveal determinants of oscillator cell fate.

\section{Methods}

\section{In vitro translation}

The full-length dac open reading frame was removed from pUAS-dac [48] by digestion with EcoR1 and Xba1 and inserted into the EcoR1 and Xba1 sites of pBluescript KS(). A plasmid containing the full-length $\mathrm{Clk}$ open reading frame was described previously (Lee'98). In vitro transcription/translation (IVTT) of plasmids containing the complete dac or Clk open reading frames was carried out using (Promega, L5010) as per manufacturer's instructions by combining the following: $25 \mu \mathrm{l}$ TNT reticulocyte lysate; 2 $\mu \mathrm{l}$ TNT reaction buffer; $1 \mu \mathrm{l}$ RNA polymerase; $1 \mu \mathrm{l}$ complete amino acid mix; $1 \mu \mathrm{g}$ DNA; to $50 \mu \mathrm{l}$ with water. Samples were incubated at $30^{\circ} \mathrm{C}$ for $90 \mathrm{~min}$.

\section{Protein expression and purification}

The complete dac open reading frame was removed from pBluescript KS(-) by digestion with EcoR1 and Xho1 and inserted into the EcoR1 and Xho1 sites of pET-28(b). The resulting pET-dac plasmid was transformed into BL21(DE3) pLysS cells for protein expression. Cell lysates were purified over a His Trap FF Column (GE, 17-531901 ), and eluants containing DAC were collected and concentrated using an Amicon $100 \mathrm{kDa}$ Concentrator (Millipore, UFC9 100 08). DAC concentration was determined to be $\sim 6.3 \mu \mathrm{g} / \mu \mathrm{l}$ by spectrophotometric analysis. 


\section{Western blotting}

Flies having a normally functioning circadian clock ( white ${ }^{1118}$ ) and $C l k^{\text {Jrk }}$ flies were entrained for at least 3 days in $12 \mathrm{~h}$ light: $12 \mathrm{~h}$ dark cycles and collected at different Zeitgeber Times (ZTs), where ZT0 is lights-on and ZT12 is lights-off. Fly protein samples were prepared from heads via RBS extraction [13]. Westerns blots were prepared by electrophorescing fly head extract and IVTT DAC and CLK on Criterion pre-cast gels (BioRad) and transferring the gel to Hybond-P membranes (Amersham). Antibodies were used at the following concentrations to probe western blots: GP47, 1:2,000; GP50, 1:5,000; anti-DAC, 1:300. For pre-absorption with DAC, GP47 was incubated with the indicated amount of DAC at $4{ }^{\circ} \mathrm{C}$ overnight with shaking. Incubation with primary antibodies was done at RT for $1 \mathrm{~h}$ for both anti-CLK antibodies and anti-DAC at $4{ }^{\circ} \mathrm{C}$ overnight. Incubation with secondary antibodies was done at RT for $1 \mathrm{hr}$ at a concentration of 1:1,000 using anti-Guinea pig HRP (Sigma, A7289) or anti-mouse HRP (Sigma, A5278) for the anti-CLK and anti-DAC primary antibodies, respectively. Immnuoblots were visualized with ECL Plus (Amersham).

\section{Embryo and Larva collection and staging}

Wild-type (Canton S) flies were entrained to $12 \mathrm{~h}$ light: 12 $\mathrm{h}$ dark cycles at $25^{\circ} \mathrm{C}$ for at least 3 days in egg laying cages containing grape agar plates with yeast paste. Lights were turned off and embryos were collected on fresh plates starting at СТ9 and ending at СТ33 ( $9 \mathrm{~h}$ after subjective dawn). To determine if the circadian clock affected oscillator cell development or phase, embryos were collected on fresh plates from CT10 to CT37 ( $1 \mathrm{~h}$ after subjective dusk) or from CT22 to CT49 (1 h after subjective dawn). After collection, embryos were fixed and staged based on their morphology [49]. L1 and L3 larvae were collected at different times during LD cycles. Different larval stages were identified based on morphology [50].

\section{Immunostaining embryos}

Wild-type (Canton S) embryos were collected and dechorionated as described [51]. Embryos were fixed with 3.7\% formaldehyde in PEM buffer with pH6.9 (0.1 M PIPES pH6.9, $1 \mathrm{mM} \mathrm{MgCl}_{2}, 1 \mathrm{mM}$ EGTA) while shaking, washed with methanol, and then re-hydrated with PBST $(1 \times$ PBS, $1 \%$ BSA, $0.05 \%$ Triton X-100). Primary antibody was diluted in PBST and incubated at $4{ }^{\circ} \mathrm{C}$ overnight. The primary antibodies and dilutions used were: anti-Guinea pig polyclonal CLOCK GP50 antibody at a 1:200 dilution, and anti-rabbit polyclonal PER (gift from J. Hall) that was pre-absorbed against per ${ }^{01}$ embryos as described [52] at a 1:200 dilution. Following primary antibody incubation, embryos were washed with PBST for 30 minutes at least 6 times at room temperature. Embryos were then incubated with a fluorescently labeled secondary antibody at a 1:200 dilution at $4^{\circ} \mathrm{C}$ overnight. The following secondary anti- bodies were used: goat anti-guinea pig Cy3 (Jackson ImmunoResearch) for anti-CLOCK, and goat anti-rabbit Alexa 488 (Molecular Probes) for anti-PER. After secondary antibody incubation, the embryos were washed with PBST for 30 minutes at least 6 times at room temperature. Mounting was done using Vectashield (Vector Labs). Six or more embryos were examined at each stage. Each experiment was repeated at least 3 times with similar results. Each Z-series image is a projection of optical thickness at $2 \mu \mathrm{m}$ per optical section.

\section{Immunostaining larval CNSs and adult brains}

Dissected adult brains were processed as previously described [26]. CNSs from wild-type L3 larvae were dissected in $1 \times$ PBS with pH7.4. Dissected larval CNSs were fixed with $3.7 \%$ formaldehyde, washed, and incubated in the following primary antibodies at $4{ }^{\circ} \mathrm{C}$ overnight: mouse mAbdac2-3 (1:100 dilution), anti-Guinea pig polyclonal CLK GP50 (1:3,000 dilution), and pre-absorbed anti-rabbit polyclonal PER (1:30,000 dilution). More concentrated CLK GP50 antibody (1:1000 dilution) was used to detect CLK in Clk ${ }^{\text {Jrk }}$ larve. After primary antibody was removed, the samples were washed, then incubated with fluorescently labeled secondary antibodies (diluted $1: 200)$ at $4^{\circ} \mathrm{C}$ overnight. The following secondary antibodies were used: goat anti-mouse Alexa 647 (Molecular Probes) for mAbdac2-3, goat anti-guinea pig Cy-3 (Jackson ImmunoResearch Laboratories, Inc.) for anti-CLOCK, and goat anti-rabbit Alexa 488 (Molecular Probes) for PER.

\section{Confocal microscopy}

Embryos, larval CNSs, and adult brains were imaged using a Zeiss LSM310 or an Olympus FV1000 confocal microscope. Serial optical scans were obtained at $2 \mu \mathrm{m}$ intervals and organized using FV1000 confocal software to generate Z-stack images. Images were processed using Adobe Photoshop.

\section{Abbreviations}

PER: PERIOD protein; CLK: CLOCK protein; CYC: CYCLE protein; DAC: DACHSHUND protein; ES: embryonic stage; ZT: Zeitgeber Time; CT: Circadian Time; IVTT: in vitro transcription/translation; W.T.: wild-type; KCs: Kenyon Cells; CNS: Central Nervous System; VNC: ventral nerve chord; OL: optic lobe; L3: $3^{\text {rd }}$ larval instar; L1: $1^{\text {st }}$ larval instar; LD: $12 \mathrm{~h}$ light: $12 \mathrm{~h}$ dark; s-LN $\mathrm{LN}_{\mathrm{v}}$ : small ventral lateral neurons; l- $\mathrm{LN}_{\mathrm{v}} \mathrm{s}$ : large ventral lateral neurons; $\mathrm{LN}_{\mathrm{d}} \mathrm{s}$ : dorsal lateral neurons; $\mathrm{DN}_{1}$ s: dorsal neuron $1 \mathrm{~s}$; $\mathrm{DN}_{2} \mathrm{~s}$ : dorsal neuron $2 \mathrm{~s} ; \mathrm{DN}_{3} \mathrm{~s}$ : dorsal neuron $3 \mathrm{~s}$.

\section{Authors' contributions}

$\mathrm{JHH}$ carried out most of the immunostaining experiments, generated and tested antibodies, participated in the design of the study, and drafted the manuscript. FN 
defined conditions for the immunostaining experiments, carried out some of the immunostaining experiments, participated in the design of the study and data interpretation, and helped to draft the manuscript. PT carried out the western analysis, generated plasmids for protein overexpression, and purified protein. PEH conceived of the study, and participated in its design and coordination and helped to draft the manuscript. All authors read and approved the final manuscript.

\section{Acknowledgements}

We thank Jeff Hall for providing anti-PER antibody and Graham Mardon for providing the $\mathrm{dac}^{03}$ null mutant and GFP balancer strains. We are indebted to Patrick Callaerts, Brigitte Dauwalder, Gregg Roman, and members of the Hardin lab for helpful discussions, the Texas A\&M Microscopy and Imaging Center for access to the FVI000 confocal microscope, Michael Rea for use of his Zeiss LSM 310 confocal microscope, and to Lily Bartoszek for proofreading the manuscript. This work was supported by NIH grant NSO5 I 280 to PEH.

\section{References}

I. Hardin PE: The circadian timekeeping system of Drosophila. Curr Biol 2005, I 5(I 7):R7|4-722.

2. Hardin PE: Essential and expendable features of the circadian timekeeping mechanism. Curr Opin Neurobiol 2006, 16(6):686-692.

3. Yu W, Hardin PE: Circadian oscillators of Drosophila and mammals. / Cell Sci 2006, I I 9(Pt 23):4793-4795.

4. Allada R, White NE, So WV, Hall JC, Rosbash M: A mutant Drosophila homolog of mammalian Clock disrupts circadian rhythms and transcription of period and timeless. Cell 1998, 93(5):79|-804.

5. Darlington TK, Wager-Smith K, Ceriani MF, Staknis D, Gekakis N, Steeves TD, Weitz CJ, Takahashi JS, Kay SA: Closing the circadian loop: CLOCK-induced transcription of its own inhibitors per and tim. Science 1998, 280(5369): 1599-1603.

6. Akten B, Jauch E, Genova GK, Kim EY, Edery I, Raabe T, Jackson FR: A role for CK2 in the Drosophila circadian oscillator. Nat Neurosci 2003, 6(3):25I-257.

7. Kloss B, Price JL, Saez L, Blau J, Rothenfluh A, Wesley CS, Young MW The Drosophila clock gene double-time encodes a protein closely related to human casein kinase lepsilon. Cell 1998 94(I):97-107.

8. Lin JM, Kilman VL, Keegan K, Paddock B, Emery-Le M, Rosbash M, Allada R: A role for casein kinase 2alpha in the Drosophila circadian clock. Nature 2002, 420(69 I7):8|6-820.

9. Price JL, Blau J, Rothenfluh A, Abodeely M, Kloss B, Young MW: double-time is a novel Drosophila clock gene that regulates PERIOD protein accumulation. Cell I998, 94(I):83-95.

10. Martinek S, Inonog S, Manoukian AS, Young MW: A role for the segment polarity gene shaggy/GSK-3 in the Drosophila circadian clock. Cell 200I, I05(6):769-779.

1I. Lee C, Bae K, Edery I: The Drosophila CLOCK protein undergoes daily rhythms in abundance, phosphorylation, and interactions with the PER-TIM complex. Neuron 1998 2 I(4):857-867.

12. Lee C, Bae K, Edery I: PER and TIM inhibit the DNA binding activity of a Drosophila CLOCK-CYC/dBMALI heterodimer without disrupting formation of the heterodimer: a basis for circadian transcription. Mol Cell Biol 1999, 19(8):5316-5325.

13. Yu W, Zheng H, Houl JH, Dauwalder B, Hardin PE: PER-dependent rhythms in CLK phosphorylation and E-box binding regulate circadian transcription. Genes Dev 2006, 20(6):723-733.

14. Kadener S, Stoleru D, McDonald M, Nawathean P, Rosbash M Clockwork Orange is a transcriptional repressor and a new Drosophila circadian pacemaker component. Genes Dev 2007, 2I(I3): I675-I686.

15. Lim C, Chung BY, Pitman JL, McGill JJ, Pradhan S, Lee J, Keegan KP, Choe J, Allada R: Clockwork orange encodes a transcriptiona repressor important for circadian-clock amplitude in Drosophila. Curr Biol 2007, 17( ( 2): 1082-1089

16. Matsumoto A, Ukai-Tadenuma M, Yamada RG, Houl J, Uno KD, Kasukawa T, Dauwalder B, Itoh TQ, Takahashi K, Ueda R, Hardin PE, Tanimura $T$, Ueda HR: A functional genomics strategy reveals clockwork orange as a transcriptional regulator in the Drosophila circadian clock. Genes Dev 2007, 2 I (13): 1687-I700.

17. Richier B, Michard-Vanhee C, Lamouroux A, Papin C, Rouyer F: The clockwork orange Drosophila protein functions as both an activator and a repressor of clock gene expression. J Biol Rhythms 2008, 23(2): 103-116.

18. Blau J, Young MW: Cycling vrille expression is required for a functional Drosophila clock. Cell 1999, 99(6):66I-67I.

19. Cyran SA, Buchsbaum AM, Reddy KL, Lin MC, Glossop NR, Hardin PE, Young MW, Storti RV, Blau J: vrille, PdpI, and dClock form a second feedback loop in the Drosophila circadian clock. Cell 2003, I I 2(3):329-34I.

20. Glossop NR, Houl JH, Zheng H, Ng FS, Dudek SM, Hardin PE: VRILLE feeds back to control circadian transcription of Clock in the Drosophila circadian oscillator. Neuron 2003, 37(2):249-26I.

21. Glossop NR, Lyons LC, Hardin PE: Interlocked feedback loops within the Drosophila circadian oscillator. Science 1999 286(5440):766-768.

22. Sehgal A, Price J, Young MW: Ontogeny of a biological clock in Drosophila melanogaster. Proc Natl Acad Sci USA 1992, 89(4): | $423-1427$

23. Kaneko M, Helfrich-Forster C, Hall JC: Spatial and temporal expression of the period and timeless genes in the developing nervous system of Drosophila: newly identified pacemaker candidates and novel features of clock gene product cycling. J Neurosci 1997, I7( 17):6745-6760.

24. James AA, Ewer J, Reddy P, Hall JC, Rosbash M: Embryonic expression of the period clock gene in the central nervous system of Drosophila melanogaster. Embo J 1986, 5(9):23।3-2320.

25. Liu X, Lorenz L, Yu QN, Hall JC, Rosbash M: Spatial and temporal expression of the period gene in Drosophila melanogaster. Genes Dev 1988, 2(2):228-238.

26. Houl JH, Yu W, Dudek SM, Hardin PE: Drosophila CLOCK Is Constitutively Expressed in Circadian Oscillator and NonOscillator Cells. J Biol Rhythms 2006, 2 I(2):93-103.

27. Davis RL: Olfactory memory formation in Drosophila: from molecular to systems neuroscience. Annu Rev Neurosci 2005, 28:275-302

28. Kurusu M, Nagao T, Walldorf U, Flister S, Gehring W], FurukuboTokunaga K: Genetic control of development of the mushroom bodies, the associative learning centers in the Drosophila brain, by the eyeless, twin of eyeless, and Dachshund genes. Proc Natl Acad Sci USA 2000, 97(5):2। 40-2। 44.

29. Martini SR, Roman G, Meuser S, Mardon G, Davis RL: The retinal determination gene, dachshund, is required for mushroom body cell differentiation. Development 2000, I 27( I 2):2663-2672.

30. Noveen A, Daniel A, Hartenstein V: Early development of the Drosophila mushroom body: the roles of eyeless and dachshund. Development 2000, I 27(16):3475-3488.

31. Chen R, Amoui M, Zhang Z, Mardon G: Dachshund and eyes absent proteins form a complex and function synergistically to induce ectopic eye development in Drosophila. Cell 1997, 9I(7):893-903.

32. Kaneko M, Hall JC: Neuroanatomy of cells expressing clock genes in Drosophila: transgenic manipulation of the period and timeless genes to mark the perikarya of circadian pacemaker neurons and their projections. J Comp Neurol 2000, 422(I):66-94.

33. Mardon G, Solomon NM, Rubin GM: dachshund encodes a nuclear protein required for normal eye and leg development in Drosophila. Development 1994, I 20(1 2):3473-3486.

34. Helfrich-Forster C, Shafer OT, Wulbeck C, Grieshaber E, Rieger D, Taghert P: Development and morphology of the clock-geneexpressing lateral neurons of Drosophila melanogaster. Comp Neurol 2007, 500(I):47-70.

35. Shafer OT, Helfrich-Forster C, Renn SC, Taghert PH: Reevaluation of Drosophila melanogaster's neuronal circadian pacemakers reveals new neuronal classes. J Comp Neurol 2006, 498(2): $180-193$. 
36. Beaver LM, Rush BL, Gvakharia BO, Giebultowicz JM: Noncircadian regulation and function of clock genes period and timeless in oogenesis of Drosophila melanogaster. J Biol Rhythms 2003, I 8(6):463-472.

37. Helfrich-Forster $C:$ The neuroarchitecture of the circadian clock in the brain of Drosophila melanogaster. Microsc Res Tech 2003, 62(2):94-102.

38. Silver SJ, Rebay I: Signaling circuitries in development: insights from the retinal determination gene network. Development 2005, I32(1):3-13.

39. Zhao J, Kilman VL, Keegan KP, Peng Y, Emery P, Rosbash M, Allada R: Drosophila Clock Can Generate Ectopic Circadian Clocks. Cell 2003, I 13:755-766.

40. Park JH, Helfrich-Forster C, Lee G, Liu L, Rosbash M, Hall JC: Differential regulation of circadian pacemaker output by separate clock genes in Drosophila. Proc Natl Acad Sci USA 2000, 97(7):3608-36/3.

41. Crews ST, Thomas JB, Goodman CS: The Drosophila singleminded gene encodes a nuclear protein with sequence similarity to the per gene product. Cell I988, 52(I):I43-I5I.

42. Hardin PE, Hall JC, Rosbash M: Feedback of the Drosophila period gene product on circadian cycling of its messenger RNA levels. Nature 1990, 343(6258):536-540.

43. Zerr DM, Hall JC, Rosbash M, Siwicki KK: Circadian fluctuations of period protein immunoreactivity in the CNS and the visual system of Drosophila. J Neurosci 1990, 10(8):2749-2762.

44. Klarsfeld A, Malpel S, Michard-Vanhee C, Picot M, Chelot E, Rouyer F: Novel features of cryptochrome-mediated photoreception in the brain circadian clock of Drosophila. J Neurosci 2004, 24(6): | 1468- 1477.

45. Benito J, Zheng $\mathrm{H}$, Hardin PE: PDPIepsilon functions downstream of the circadian oscillator to mediate behavioral rhythms. J Neurosci 2007, 27( I 0):2539-2547.

46. Sprecher SG, Reichert H, Hartenstein V: Gene expression patterns in primary neuronal clusters of the Drosophila embryonic brain. Gene Expr Patterns 2007, 7(5):584-595.

47. Younossi-Hartenstein A, Nguyen B, Shy D, Hartenstein V: Embryonic origin of the Drosophila brain neuropile. J Comp Neurol 2006, 497(6):98I-998.

48. Tavsanli BC, Ostrin EJ, Burgess HK, Middlebrooks BW, Pham TA, Mardon G: Structure-function analysis of the Drosophila retinal determination protein Dachshund. Dev Biol 2004, 272(I):23I-247.

49. Campos-Ortega JA, Hartenstein V: The Embryonic Development of Drosophila melanogaster Berlin: Springer-Verlag; 1997.

50. Roberts DB: Drosophila: A Practical Approach Oxford: Oxford University Press; 1998.

5I. Sullivan W, Ashburner M, Hawley RS: Drosophila Protocols Cold Spring Harbor: Cold Spring Harbor Laboratory Press; 2000.

52. Cheng $Y$, Hardin PE: Drosophila photoreceptors contain an autonomous circadian oscillator that can function without period mRNA cycling. J Neurosci 1998, 18(2):74I-750.

Publish with Bio Med Central and every scientist can read your work free of charge

"BioMed Central will be the most significant development for disseminating the results of biomedical research in our lifetime. "

Sir Paul Nurse, Cancer Research UK

Your research papers will be:

- available free of charge to the entire biomedical community

- peer reviewed and published immediately upon acceptance

- cited in PubMed and archived on PubMed Central

- yours - you keep the copyright
BioMedcentral 